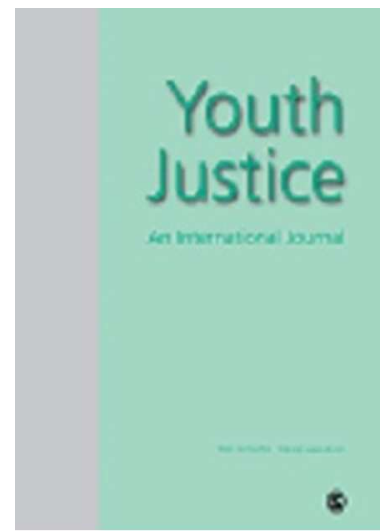

\title{
Juvenile Facility Staff Contestations of Change
}

\begin{tabular}{|c|l|}
\hline Journal: & Youth Justice \\
\hline Manuscript ID & YJJ-18-0018 \\
\hline Manuscript Type: & Original Article \\
\hline Keywords: & reform, decarceration, resistance, frontline staff, behavioural control \\
\hline Abstract: & $\begin{array}{l}\text { This article explores juvenile facility frontline staff members' contestations } \\
\text { of change to custodial practices aimed at reducing restraints, introducing } \\
\text { trauma-informed practices, and downsizing juvenile facilities. Drawing } \\
\text { from qualitative research about frontline staff members in a U.S. state } \\
\text { undergoing reform, the article points to the ways that the reforms } \\
\text { challenge staff members' investments in behavioral control practices as a } \\
\text { vehicle for achieving order and control in their everyday lives as } \\
\text { workers. It also points to shifts in the broader political economy of } \\
\text { punishment at the local, facility level, and the subsequent impact on staff } \\
\text { member perceptions of order, control and criminality. }\end{array}$ \\
\hline
\end{tabular}

\section{SCHOLARONE ${ }^{\text {m }}$}

Manuscripts 


\section{Juvenile Facility Staff Contestations of Change}

In recent years, states across America have engaged in a significant project of decarceration and devolution of their systems and systematic reforms of the residential facilities that remain, spurred in part by the fiscal pressures on state governments that emerged in the wake of the 2008 recession, but also under pressure from advocacy groups and foundations who have promoted closure and reform (McCarthy et al., 2016, Horowitz and Carlock, 2017, Abrams, 2013). These reforms in youth custody have been partially inspired by a model of youth custody developed in Missouri, which has smaller facilities, more 'humane' environments and trauma-oriented care (Mendel, 2010, Moore, 2009). But the reforms have also been happening in a number of Western European contexts (Kelly and Armitage, 2014, Horowitz and Carlock, 2017, Schiraldi, 2018, Dunkel, 2015).

On their face, the reforms to youth custody systems in the United States seemingly represent a 'swing' away from a punitive and towards a more rehabilitative and therapeutic approach to young people (Bernard and Kurlychek, 2010). Youth justice reformers have argued that this 'swing' is a necessary one away from a period in the 1990s where large classes of young people - particularly young people of color - were overcriminalized and punished (Larson and Carvente, 2017). However, the pendulum theory of criminal justice reform, which suggests that there are 'swings' or cycles in systems from punitive to rehabilitative, may not be an accurate representation of what is actually a complex, contested and contradictory process. Goodman, Page and Phelps argue for an 'agonistic,' as opposed to linear, model of change which recognizes that penal developments are a "product of struggle between actors with different types and amounts of power" (2017: 8). They point to the varied actors, or 'agonists', who operate in the penal landscape and often contest change. Drawing from qualitative interviews that took place with staff members in 
residential juvenile facilities in the United States during a period of reform, I argue that juvenile facility staff contestations of reform shed light on the difficult and fraught process of trying to meet children's needs in a custodial context that is overwhelmingly focused on their deeds. I also point to transformations in the broader political economy outside of the facilities, and their impact on staff contestations of change. I argue that this was a context where increased job insecurity, particularly amongst public sector workers, set anxieties about the stability of their work into motion. These anxieties arguably solidified staff members' investments in what they perceived to be the more enduring aspects of their work, those rooted in the idea that custodial interventions are an effective form of punishment. It also demonstrated their resistance to the idea that custodial interventions can meet the emotional needs of young people.

\section{Residential Reforms}

New York State embarked on a large-scale process of juvenile justice reforms around 2007 (Task Force on Transforming Juvenile Justice, 2009). The reforms to the state's residential juvenile facilities began when Eliot Spitzer became the Democratic governor of the state in 2007 and appointed a new commissioner of the state's Office of Children and Family Services (OCFS), Gladys Carrión. OCFS is responsible for the state's juvenile facilities as well as its child welfare services. Carrión set out to reform and close the state's juvenile facilities. The state ultimately closed down 31 facilities and reduced its admissions numbers from 1,692 young people in 2007 to just 338 young people in 2016 (National Juvenile Justice Network and Texas Public Policy Foundation, 2013, Office of Children and Family Services, 2016). The state also engaged in a process of realignment, closing their state-level juvenile facilities and shifting young people to locally-controlled, often privatelycontracted facilities, also consistent with national trends (Cate, 2016, Butts and Evans, 2011). 
States across the United States have cited several reasons for downsizing their juvenile facilities, from fiscal concerns, to poor conditions of confinement. State officials pointed to research on the deleterious effects of confinement on young people, particularly in squelching their development, embedding the labeling effects of system contact, separating them from their families, and exposing them to poor conditions of confinement (see, e.g. Gatti et al., 2009, Nagin, 2009).

\section{Reform Rhetoric}

Much of the discourse about the recent reforms in juvenile justice systems has suggested that a shift has taken place away from an ostensibly 'harsh' and punitive system towards more therapeutic systems. The reform rhetoric has also elevated the role of the 'community' in producing positive change, and emphasized community-based alternatives to incarceration, connecting the idea of 'community' to treatment (Cate, 2016, Armstrong, 2002). Most reformers point to harms in custody as ones involving overt forms of punitive control, such as the practices of room confinement, physical and sexual abuse by guards, and the overuse of physical restraints and force (Ryan and Schiraldi, 2018). The reform strategy is thus largely connected to and dependent upon the idea that not only can the community 'cure,' but that a small number of reformed residential juvenile facilities can effectively deliver 'care.' Yet, scholars are increasingly beginning to ask whether indeed it is ever possible to provide care in contexts of control, particularly in contexts where putatively therapeutic practices can be experienced as a form of punishment (Phoenix, 2009, Fader, 2008, Myers, 2013).

Political Economy

The political and economic backdrop to the reforms that took place in the juvenile facilities is critical in contextualizing the role that frontline staff members played in 
responding to the reforms. Between 2006 and 2015, there was a 49\% drop in violent crime by juveniles across the United States; the rate at which young people were sentenced to out of home placement also dropped by at least 50\% in 24 U.S. states; in New York, the percent decline in commitments during this time was 67\% (Horowitz and Carlock, 2017). The decline in the numbers of young people being arrested also meant that the cost of care in New York State rose, as the number of beds in placement, as well as the numbers of staff, held relatively constant. When the 2008 recession struck, the state was under enormous pressure to close what were identified to be very costly forms of state-funded care.

Closing juvenile facilities also involved laying off the staff members who worked in them. Staff in the juvenile facilities were members of the state's largest public sector unions, which also represented workers in other sectors that faced job cuts. For many years, these public sector jobs had helped to nourish the largely deindustrialized Northern part of the state, which had gone into severe decline in the post-World War II years (Castellani, 2005). As the manufacturing jobs declined, state jobs increased during the 1960s as Governor Rockefeller inflated the state's public administrations and authorities (Castellani, 2005: 125). Government employment grew by more than a third from 1965 to 1972 in upstate New York, while manufacturing jobs declined significantly (Castellani, 2005: 127). Public sector positions, particularly those in the juvenile justice system and prisons, offered some hope for rural economic deprivation, despite the fact that some analysts have pointed to their inability of these jobs to deliver on such hope (King et al., 2003).

When the Governor of New York State proposed closing a number of the state's juvenile facilities, and laying off its staff members, many of the staff in those facilities, and their unions, opposed such changes, and this opposition was well-documented in the public media (Anich, 2009, McAvoy, 2008, Ference, 2008, ReadMedia, 2012). Staff member unions 
resisted the reforms at the state level, lobbying in Albany and organizing significant political resistance.

Media reports documented the desire of residential facility workers to maintain their well-paid jobs in the face of few job prospects in the rural communities they came from, and the need for political conservatives to lock up wayward children rather than allow them to serve their time in the community. Equally well-documented was the position of system reformers, who spoke in public and the media about what was termed the "culture of violence" that existed among staff members in the residential facilities. Media sources around the state opined on the relationship between staff 'cultures' of resistance and the levels of brutality that existed in the facilities (King, 2010, New York Times, 2010), and the staff members were aware of their negative characterization in the public media.

As he built toward his strategy of realignment and decarceration, the newly-elected

Governor Andrew Cuomo noted in his State of the State speech in January 2011:

I understand the importance of keeping jobs especially in upstate New York. I also understand that that does not justify the burden on the taxpayer and the violation of civil rights of the young person who is in a program that they don't need where they're not being treated hundreds of miles from their home just to save state jobs. An incarceration program is not an employment program.

Cuomo's father, Mario Cuomo, led the state's largest prison-building efforts in history; in this new era of reform, upstate workers were portrayed as a key obstructionist force in the reforms. Cuomo recognized that if he could build public antipathy towards rural prison workers, he might build more public support for legislation that he sought to pass in a predominantly Republican state legislature in which he faced significant opposition from lawmakers who represented the districts which held the facilities.

This was not the first period of juvenile facility decarceration in which the state faced opposition. During the 1970 s and 1980s, the state engaged in significant downsizing and 
reform, shifting some young people to community-based facilities, implementing new practices and experimental programs in confinement, and implementing diversionary programs (McGarrell, 1988). This paralleled a large-scale process of deinstitutionalization of the state's psychiatric hospitals. In both periods, the state's public sector unions also engaged in campaigns advocating for the preservation of their jobs, and the history of that period was well known to many of the labor union activists who were involved in the work against the current closures (see also Thompson, 2011, Page, 2011).

Penal policy is intimately tied to the functioning of the political economy (Gottschalk, 2010). Gottschalk (2010) cautions against the assumption that economic crises alone will necessarily result in full scale decarceration, pointing not only to the economic and political logics that sustain incarceration, but also the cultural and social foundations of punitive policies, as the bounce back of the population of young people in juvenile facilities in the years following the reforms of the 1960 s and 1970s can attest. Similarly, Grasso (2017) has argued that current state-level efforts to revive the 'rehabilitative ideal' often mask the "punitive facets" of what he terms "rehabilitative penology" (394). Grasso argues that these ideologies of punitiveness which center notions of 'incorrigibility' at the heart of the idea of the offender have long been embedded in official state discourses, even as states ostensibly tilt towards 'rehabilitation' over punishment. This work raises important questions about the relationship between reforms in theory and those in practice, and the role that organized labor plays in contesting reforms - and revealing their underlying logics-within the context of a fraught political and economic landscape.

Extant Research

This article mines the perceptions of frontline staff about juvenile justice reforms in order to better understand the relationship that workers may play in revealing the shape of 
punishment in a context where rehabilitation is leveraged as an ideal by those doing the reforms. Sociology of punishment scholars have increasingly recognized that mass imprisonment is a highly localized issue, and that we must begin to challenge narratives and ideas about grand 'systems’ of punishment (Garland, 2013, Goodman et al., 2017, Harcourt, 2014). Recent work has pointed to the role of state actors in their responses to and within systems of punishment and social control (Garland, 2013, Cheliotis, 2006). Scholars have highlighted the practices and perspectives of state actors, such as prosecutors, prison guards, and police officers, in the context of a penal field that is often deeply contested and dynamic, and where punishment and 'treatment' often merge (Page, 2011, Rubin and Phelps, 2017, Barker, 2009, Lacey and Soskice, 2015, Pfaff, 2017, Werth, 2017, Rudes et al., 2011, Stuart, 2016). Youth justice scholars have revealed the role that workers play in contesting and managing reforms, expressing divergent and sometimes contradictory narratives about punishment and change, and shaping ideas about youth criminality (Kelly and Armitage, 2014, Gray, 2013, Ward and Kupchik, 2008). However, much of this work has focused on workers in adult contexts, or youth justice workers in the community; very little research has examined the role of workers in custodial contexts in youth justice (although see Inderbitzen, 2006, Abrams and Anderson-Nathe, 2013). It is arguable that the custodial contexts can reveal a great deal about the penal landscape at the 'deep end' of the juvenile justice system in ways that elucidate our knowledge about the roles that custody and removal play in the penal imagination.

The literature on 'street level' bureaucracy has helped us to understand the roles that frontline workers play in mediating between policy and practice (Lipsky, 1980). Line staff and management often have different language, cultures, and understandings about the everyday practices of imprisonment and treatment than administrators and reformers, and 
these understandings can help to reveal the tensions and contradictions in policy and practice, and the power of worker identity and positionality in mediating reforms (WatkinsHayes, 2009a, Morrill and Rudes, 2010, Cheliotis, 2006).

Coming from a psychosocial approach, Crawley's (2004) research on the working lives of prison officers has revealed that the officers engage in a significant amount of emotion management. She argues that prisons are inherently emotional places - prisoners are dealing with the acute stresses and pains of imprisonment, and these pains form the "bedrock" on which the social cohesion of the institution is built (Western, 2007: xii). Other scholars have explored the role conflicts and stressors that exist within prison and juvenile facility landscapes, and the strategies that staff members engage in to manage those conflicts (between, for example, nurture and discipline) (Tracy, 2004, Inderbitzen, 2006, Dowden and Tellier, 2004). Yet juvenile facility frontline staff occupy a role that is different from prison 'guards': as individuals working in settings that are ostensibly treatment-oriented, yet also custodial, they walk a tightrope between 'care' and 'control'; they are neither guards nor social workers (Inderbitzen, 2006). Thus, any examination of their work must take into consideration the particular context and meanings of what that work involves.

Within the sociology of organizations, researchers have studied the informal networks and forms of power that operate within formal organizational structures (Blau and Scott, 1962). According to the typology of organizations developed by sociologists Peter Blau and W. Richard Scott, juvenile residential facilities are formal organizations, organized around a central purpose, yet which contain informal organizations within it which are organized around their own practices, values, norms and social relations (Blau and Scott, 1962: 6). The informal responses to formal organizational structures reveal how social relations are structured and the cultures that develop amongst workers in response to the 
This article is based on research conducted in New York's juvenile justice system over a period of three years. The initial research was aimed at understanding the dynamics of incarceration and rehabilitation in juvenile justice settings from the perspectives of young people (Author, 2018). The second research study was aimed at understanding the barriers to organizational change in imprisonment, from the perspective of juvenile facility staff.

The first part of the research, which took place from 2008 to 2009, focused on young people's experiences within three juvenile facilities, and involved immersive qualitative research with 29 young people. The second part of the research focused on juvenile facility staff. This research involved over 40 site visits to facilities and interviews with over 75 staff members from the beginning of 2011 until the fall of 2012. Two residential juvenile facilities were the focus of the second study. This article draws more broadly from observational research and data from seven juvenile facilities across New York State, as well as participant observation in local advocacy gatherings, policy-reform meetings and presentations, meetings with state-level administrators, and legislative sessions and advisory group meetings. I obtained access to the state's residential juvenile facilities through the Office of Children and Family Services (OCFS). 
Residential juvenile facilities are located across New York State, primarily in rural parts of the state, and while they are operated by the central administration, based in Albany, they are managed at the local level by a set of facility directors and administrators. The facilities ranged in size, from having just a handful of young people, to the larger facilities, which had close to 200 children. I worked with the state agency on site selection for both studies. Facilities were identified for their relevance for the study of the impact of the reforms: a small, rural facility for boys, which was next door to a recently-closed facility, was selected, identified as "Edgewood" in this article, as well as a larger, congregate care-style facility for boys charged as adults, identified as "Hooper" in this article. Both facilities were in the process of implementing facility-based reforms.

I engaged in observational fieldwork in multiple settings in the institution, from the administrative offices, to the security and control buildings, to units, classrooms, and playing fields and at different times of day, from morning to night. I also conducted semi-structured interviews with staff members; I engaged in a mix of purposive and snowball sampling in order to develop the participant pool, assessing the diversity of the pool in terms of gender, age, race/ethnicity, position and length of time in the system as I progressed in the field research. The sample included direct line staff (known as Youth Development Aides, or YDAs), youth counselors, assistant directors, directors, security staff administrators, teachers, recreational staff, social workers, staff psychologists, mental health unit staff, central office administrators, and union administrators. In the second study, which was an action research study, aimed at providing the state with insights into staff perspectives on reform, I used an Appreciative Inquiry interview protocol about staff experiences in custody (Liebling and Arnold, 2004). ${ }^{\mathrm{i}}$ Appreciative Inquiry is "an approach to organizations which is 
based on strengths rather than weaknesses, on visions of what is possible rather than what is not possible" (Liebling and Price, 2001: 6, see also Cooperrider and Whitney, 2007).

I employed a grounded theory approach to the collection, coding, and analysis of the data. I developed an initial set of codes from the field notes and interview data, drafted integrative memos about the codes, and then refined the codes through secondary analysis. I used the qualitative software Dedoose to analyze the data. The data on which this article is based draws in particular from interviews with Youth Development Aides, or the frontline staff, and focuses on three of the themes that emerged from the interview data-those related to staff perceptions of 'structure,' control, and treatment in the context of reforms. Restraints and their Relationship to 'Structure'

Physical restraints and room seclusion are used in a variety of settings, from prisons, to juvenile facilities, to psychiatric hospitals as an effort to ensure the physical safety. However, researchers and practitioners increasingly recognized the risks of these practices, from their uses as forms of discipline and punishment, as opposed to the preservation of safety, to physical harm and even death (Government Accountability Office, 2009, DeMasi and Boyd, 2007). In late 2006, a boy died in a residential juvenile facility in New York after being restrained by staff members, triggering an investigation by the Department of Justice and a re-analysis of the use of restraints. The state subsequently decided to engage in substantial reforms of the restraint system, setting key performance targets for each facility and monitoring the numbers of restraints they engaged in, minimizing the criteria which would trigger a restraint, and, in a number of restraint cases, initiating a child abuse investigation of staff members who engaged in restraints. The staff were encouraged to use de-escalation strategies and other forms of crisis intervention instead. 
This effort by the central office to reform the restraint practices was officially driven by a desire to protect young people and limit and restrict physical forms of punishment. Yet, it was overwhelmingly experienced by staff as a formal effort by the central state office to monitor and control their work, and a number of staff contested the practice. Conversations about the policy change pervaded facility life. A number of staff members interpreted the change as a restriction on their rights to "lay their hands" on young people (a Black male Youth Development Aide (YDA), a frontline staff member, at Hooper, the larger facility, had been told by facility administrators "from now on, it's hands off.") Many staff members interpreted this shift as one which "tied their hands" and exposed them to more risk; in other words, their perception was that they had moved from a system where they could use physical restraints as a tool for controlling unruly young people, and that the new reforms had forced them into a system where they could no longer use that 'tool' and were thus at risk of having the kids physically control them. According to a white male YDA at Edgewood, referring to the leader, Gladys Carrión:

Then Gladys got in and it just spiraled right out of control because there was all these, "Don't put your hands on kids." There were eight different reasons that you could put your hands on a kid and it went down to three now which I'm gonna defend myself and I'm not gonna let a kid hurt somebody else and when two kids fight what do you do, you get between them and get hit.

Staff members often spoke nostalgically about an 'old' system which involved a greater use of restraints, and which they described as 'structured.' The new system, they said, was deeply unstructured and unsafe. A white male YDA in his 20s who had recently started working at Edgewood had been told by a friend that if he worked at Edgewood, " you can beat the shit out of them [the residents]" but that he quickly realized under the new set of policies that this was not possible. A white male Youth Counselor, who had worked in the system for almost 30 years, and who had been moved to Edgewood after his boot-camp 
style facility had closed, argued, of the boot camp model, "that was a steel rod but it worked. It did." He spoke about the high number of restraints under that system, and said "It was structured and it was disciplined." This staff member, who hadn't read the empirical research highlighting the failures of boot camps (Bottcher and Ezell, 2005), only saw that a model that he felt 'worked' had been shut down by people who didn't work on the ground, as he did.

This assertion of ground-level knowledge over and above technocratic wisdom played a powerful role in the facility landscape and became one of the strategies staff members engaged in to contest institutional reforms. A number of facility staff members viewed efforts at reform as those which involved largely liberal bureaucrats imposing rules and regulations in their daily lives, which they felt ultimately inhibited them and didn't respect their desires for the facilities to be places of self-government and informal, unregulated control and discretion. A number of the staff members perceived the bureaucrats to be out of touch with what they felt 'worked' to instill order in facility life; tellingly, they seldom acknowledged that the changes to the restraint practices were aimed at protecting young people, but instead asserted that the practices failed to protect staff. Some staff members viewed physical forms of control over young people (restraints) to be more effective than what they believed were more complex and difficult, and less easily achievable forms of control- persuading young people to calm down or manage their anger by talking to them.

A number of staff members and administrators promulgated the narrative that the individuals being punished in the reformed system were them, not the children. They pointed to two direct strains of the perceived 'punishment': one was through a monitoring and oversight system that was implemented in order to evaluate the uses of restraints in each 
facility. A union representative based at a central office in Albany argued that "people in the facilities get mixed messages from the directors down... You know, the directors are told the most important thing is to get your restraint records, your restraint numbers down, so you ignore things." Rumors abounded, particularly at Edgewood, that the reason why facilities were closing was because they couldn't get their restraint numbers down. As the official policy involved contacting the child abuse complaint service after a restraint had been conducted, initiating an investigation procedure, staff members saw that the response to their use of a restraint was punishment, through suspension or even termination. Some staff members responded by avoiding doing restraints or verbal de-escalation strategies, arguing that they felt 'safer' in doing nothing. Although the staff members were a heterogeneous group of individuals, and often diverged in their perspectives on and about particular young people, or their relative investment in the day-to day-work, there was a relatively consistent narrative expressed by staff members that the facilities had lost their 'structure' in the context of the reforms.

\section{Theories of Incivility}

In the context of reforms that sought to give young people more privileges in facility life, and to loosen the previously rigid structures of discipline and control, a number of staff members asserted the need for strict discipline in order to maintain order in facility life. This was despite their more quiet admissions that the facilities often felt more 'orderly' and calm when young people were engaged in purposeful activities, such as sports events or educational and creative programming. However, in more formal interview settings, a number of staff members embraced the idea that if low-level incivilities-young people's trousers riding below their waists, shirts untucked, minor rule violations - were consistently addressed in the facilities, then larger-level disorders would be prevented; they thus 
expressed open resentment about a rule change ending the practice of young people holding their hands behind their backs when they walked through the facility. Their ideas seemed to derive from a vague application of neo-conservative logics about the need to punish incivilities, manage risky subjects, and exert control (Wilson and Kelling, 1982, O'Malley, 2010). As Sampson and Raudenbush (2004) have argued, notions of and responses to 'disorder' are shaped by the racial and economic context of that perceived disorder; this was important to recognize in a facility context where over $80 \%$ of the young people in care were children of color. A union representative, presenting a global view of her perspective on staff experiences, said: “And the workers aren't allowed to - not even discipline, I'm not sure discipline is the right word, but there are no consequences for low level behaviors, so it ends up escalating into bigger behaviors.”

The sense by many staff members was that when young people looked and acted deferential, then other positive benefits to facility life followed. A Black male YDA who worked at Hooper said:

Before, all moves were done before. The residents, they had their hands checked behind their backs. ... They were told to keep their pants pulled up, which they were. They were dressed in order. Their uniform was basically the same. When that came into place, they had to check their hands. Then staff here felt we had lost control at that time...

Staff members had the perception that young people were being given more privileges than punishment. A Black female YDA at the girl's facility said, "I think our structure is gone," and that "if you tell any child yes all the time, it doesn't work." She said that the "kids can't accept a 'no' nowadays," because “....the whole problem with our system is that we have no structure to help kids understand that no means no.” A black male YDA at Hooper who had worked in the system for 18 years said that he felt that there was "no more structure to hold them accountable for their actions. There are more fights, and more gang-related activities." 
He said that out of a class of 15 students, "I'm lucky if I have six of them do work." He pointed to what he felt was an unenforced prohibition on trading soaps and other commissary items in the facilities that previously would have resulted in a disciplinary write up or a loss of privileges, a failure to advance in the behavioral change system, and could even have an impact on a young person's time in custody.

Trauma-informed care

In the broader policy advocacy arena, a new discourse of 'trauma' started emerging (Branson et al., 2017). Trauma-informed care seeped its way into facility life, not necessarily as a practice, but through gossip about its impending arrival. The state adopted an approach to treatment which was focused on understanding not only the trauma that young people brought with them into the system, but also that of the staff that worked with them (Bloom, 2005).

The concept of trauma-informed care has been aimed at everything from staff practices, to institutional techniques, interventions, services, hardware and approaches. Linked to 'gender-responsive' care, these approaches aim to address individual needs that result from their experiences. Yet, some scholars have raised questions about the difficulties inherent in meeting individual needs in environments that are inherently devoted to security and containment (Kruttschnitt, 2016). As Hannah-Moffat (2006) argues, penal regimes increasingly tend to fuse ideas about 'risk' with those of 'need' in ways that serve the goals and interests of those regimes. Trauma-informed programs target 'needs' in criminalized young people, often identifying the trauma as the cause of their offending.

Residential juvenile facilities have arguably always fused risk and need, but the staff members who contested the introduction of trauma-informed practices revealed some of the ways that these practices forced them to understand young people's biographies - and the 
complex terrain of their emotional lives--in ways that were sometimes unsettling for them. This suggests that in previous regimes, the denial or obfuscation of young people's pasts allowed staff members to focus their jobs overwhelmingly on their present manifestations of 'risk.' A white male frontline staff member at Edgewood, who had been working in the system for 34 years at a set of small rural facilities, some of which had been closed, bemoaned what he saw as this more individualized approach to young people. He said "I understand that these kids are traumatized, but we are treating kids 'good' here." He spoke nostalgically about the days when he said he could ask a resident to pull their pants up, and they would do so, or when they could make educational progress while they were in the facilities, because they followed the directives of teachers. Now, he said, it is just "crowd control." Implying, like a number of other staff members, that the new approach to treatment empowered young people to be disrespectful to staff members through the acknowledgement of their histories of suffering, he said that "no one deserves to be spat at." Suggesting that the young people in past regimes were more deferential, he said "the kids used to say 'thank you sir, thank you ma'am." Yet, he said "everything is harder now,' because 'they've got a strange sense of morals." The staff members suggest here that their loss of control is related to their struggle to balance their efforts at behavioral control with that of emotion management; they alluded to a putatively simpler time, when asking young people to pull up their pants translated into institutional order and control.

Staff members themselves also grappled with their own relationships to trauma and risk, which may have compounded their reaction to—and denial of — the issue of young people's trauma. Staff member exposure to violence and injury on the job, anxiety and instability about facility closures, performance-based management culture, and the thoughoften unspoken 'riskiness' inherent in building and developing attachments to young people 
that would not be long-lasting, due to the prohibitions on contact with young people after they left facility life. Some staff felt that their 'needs' were displaced by an attention to the young people's needs. They felt that their decision to enter into work that involved its own exposure to violence and injury was a risk that they were to assume, not the state.

Many staff members perceived that the facilities had gotten more violent as a result of the reforms. Performance Based Standards data was collected from juvenile residential facilities about assaults on staff per 100 days of confinement. In a comparison between data collected from October 2009 and April 2013, eight out of eleven of those facilities saw an increase in the number of staff assaults. ${ }^{\text {ii }}$ Data is also collected about the percentage of staff members who report that they feared for their safety in the previous six months. This data is more equivocal; in seven out of the eleven facilities, there was a decline in the number of staff who felt unsafe. The facility that reported a significant increase (of approximately 23 percent of the staff feeling unsafe to 63 percent of the staff) is one that made the shift from being a bootcamp facility to a traditional residential treatment facility. That facility also faced a significant number of layoffs in 2011. Another facility that faced a significant increase in the number of staff feeling unsafe experienced an influx of youth who had significant mental health issues and were considered to be "hard to place," and staff there also felt uncertain about the future of the facility.

In the facilities, a considerable number of staff were called out on overtime during the reforms. In 2010, New York spent $\$ 14$ million on staff overtime at OCFS, a significant rise from previous years (Wurtmann, 2012). During the state fiscal crises of the 1970s, in which a similar period of deinstitutionalization occurred in juvenile facilities, states saw a similar rise in the use of overtime in correctional institutions (Wynne, 1978). Staff cited several causes for this (over) use of overtime. Some spoke about their perception that more 
staff were injured on the job as a result of the lack of 'structure' and the rise in violence in the facilities. However, others commented on the use of overtime as a 'foot dragging' strategy that some staff members engaged in -- tired and frustrated by the work, they would call in sick even if they were not sick.

Every facility reported a drop in the number of youth feeling unsafe in the previous six months, and in some cases, a quite substantial drop. This discrepancy between staff and youth perceptions of safety may reveal the impact of the reforms on these perceptions. A key scholar of organizations notes that "uncertainty and instability in an organization may be affected by the emotions of the workers within it" (Hirschorn, 1988). At Edgewood, staff had witnessed the facility next door to theirs being closed, and were fearful that their facility was on the chopping block, and a number of staff members expressed anxiety about the lack of transparency about the process of facility closures. At Hooper, a facility that was less likely to close because of its size and the population of young people it served (young people charged as adults), the staff expressed some anxiety about the shifting terrain of broader reform policies, such as a proposal to raise the age of criminal responsibility in the state, which they felt might shift the population of young people under their control, or the possibility that newer staff would be coming into the facility from those that had closed.

A Black male YDA at Hooper who had worked at the system for almost twenty years, referring to his fellow staff, said "A lot of them, seeing it on their face, they feel unsafe because they don't know what's going to happen, if they going to be supported if something does happen. It's the same thing with the residents. A lot of residents don't even feel safe. That's why the whole uproars come up a lot. They do it to get attention.”

As notions of 'violence' were unpacked, it seemed that the threat of incivility and violence felt grave to staff. The Assistant Director of Edgewood, a white man who had 
worked in the system for over 25 years, said that he felt that his staff had faced a "barrage of abuse and disrespect" from the kids, and that it was "incessant," "non-stop," and "rampant." In fact, the staff members struggled to manage in ways that many parents of teenagers struggle with the emotional landscape of adolescent resistance to adult restrictions and boundaries in their lives. Yet this 'disrespect' exists within a context in which the young people's actions are viewed within a lens of criminality, not immaturity. It is in this context, then, that staff arguably struggle to view young people as traumatized, and instead see their violence as innate. Joe Sim (2010) has pointed to the ways that 'state talk' of the violence of the so-called deviant helps to legitimate the state power used against them, particularly in confinement; he argues that prison officers themselves get recruited into this project of state violence. In this context, the individual officer who goes awry is punished, but the existing structure of state power and violence is maintained.

\section{Contradictions and Counternarratives}

Staff endorsements of punitiveness were not always matched by expressions of harsh brutality and control. Instead, they struggled to manage their ideas about the inability of the system to 'change.' For as much as they narrated a view of young people as largely incorrigible and in need of control, many facility staff members also grew very attached to them. They helped them apply to jobs and to college, they started book clubs, helped them with their homework, and would often joke and chat with them (see also Author, 2018). There were a number of staff who fell into this space; on the one hand, they expressed solidarity with other frontline staff members who felt that the system had gotten 'worse,' as had the young people, but on the other hand, they expressed a strong level of investment in the young people under the their care. Indeed, some of the staff members who expressed the strongest narratives of responsibility and bootstrapping also engaged in highly 'caring' 
work towards young people, encouraging them with their school work and emphasizing their strengths. In a context where more than $50 \%$ of the line staff in the facilities were Black and Latino (Source: OCFS data request), and $81 \%$ of the young people in the facilities in 2008 were Black and Latino (OCFS, 2008), these notions about uplift may have also been shaped by the staff members' own experiences of finding success in the face of strong barriers to social mobility (see also Watkins-Hayes, 2009b).

\section{Discussion}

This research focused on staff perspectives on facility life in the context of reforms that happened both within the facilities, aimed at making them more 'therapeutic' and less punitive, and those that happen outside of the facilities, engaged in a broader effort at deinstitutionalization. The data in this article focuses on staff perceptions of order in the context of these reforms. These perceptions to some extent reflect some enduring assumptions about the incorrigibility and criminality of criminalized children (Garland, 1985, Grasso, 2017). They also reflect the difficulty with which facility staff members assimilate new conceptualizations of young people's offending in contexts where the very nature of their work is and has been reliant on a certain denial of young people's early suffering, and a focus on the present manifestations of their pain. For many of the staff members had started working in the system in the 1990s, and the average tenure of the workers I interviewed was 17 years (the agency-wide average was 15 years). Thus, they had worked in a system that had spanned a number of 'reformers', and thus relied upon what they felt was a strategy of punishment that 'worked' through the reforms, which was largely one that centered behavioral control as punishment. Appeals to this 'common sense' of punishment remain a powerful tool in the arsenal of resistance to penal change (Phelps, 2016). 
Staff responses to the changes to the restraints policies highlighted the persistence of ideas about the efficacy of physical and instrumental forms of punishment in the life of a juvenile facility. Although a number of staff spoke about their dislike of engaging in physical restraints, and their susceptibility to injury during the process, a number of them nonetheless embraced the idea that physical restraints 'work' to control young people under their care. The staff members' responses to the reductions in the use of restraints points to the persistence of ideas about disciplinary control; their sense that they might be losing 'control' over the young people (as opposed to their reflections on the safety of young people) suggest that the practices themselves had always been viewed within the context of penal management, as opposed to youth safety.

Staff narratives about the role of reforms in leading to the decline of safety in the facilities and the rise of violence also revealed the complexity of reforms that were posed as an effort to make facilities more therapeutic. These narratives by staff of a descent into violence also existed in previous periods of decarceration and reform in New York State, and have emerged in other states. Although on their surface, the staff critiques of the reforms are suggestive of their embrace of positivist, essentializing conceptions of youth crime and criminality, these perceptions may also reflect the difficulties juvenile facility staff face when they work in environments where the very meaning and purpose of that work comes into question via the reforms. For it may be that the reforms challenge the guiding assumptions and rationalities that staff members had to embrace to make their own work and their sense of agency and control in that work - 'common sense.' As they are asked to grapple with the emotional lives of young people, when they were previously ask to focus on their behavioral control, staff members contest reforms. In a political economy where their jobs become the terrain for austerity measures, they then assert their expertise and 
experience, as well as appeal to ideas about the necessity of custody and control, as an effort to protect themselves and their jobs.

\section{REFERENCES}

Abrams, L. (2013) Juvenile Justice at a Crossroads: Science, Evidence, and Twenty-First Century Reform. Social Service Review, vol 87, no 4, pp 725-752.

Abrams, L. \& Anderson-Nathe, B. (2013) Compassionate Confinement: A Year in the Life of Unit $C$, New Brunswick, New Jersey: Rutgers University Press.

Anich, M. (2009). Tryon employees receive pink slips. The Leader-Herald.

Armstrong, S. (2002) Punishing not-for-profit: Implications of nonprofit privatization in juvenile punishment. Punishment \& Society, vol 4, no 3, pp 345-368.

Barker, V. (2009) The Politics of Imprisonment: How the Democratic Process Shapes the Way America Punishes Offenders, New York: Oxford University Press.

Bernard, T. \& Kurlychek, M. (2010) The Cycle of Juvenile Justice, New York: Oxford Universty Press.

Blau, P. \& Scott, W. R. (1962) Formal Organizations: A Comparative Approach, Palo Alto: Stanford University Press.

Bloom, S. (2005) The Sanctuary Model of Organizational Change for Children's Residential Treatment. Therapeutic Community: The International Journal for Therapeutic and Supportive Organizations, vol 26, no 1, pp 65-81.

Bottcher, J. \& Ezell, M. (2005) Examining the Effectiveness of Boot Camps: A Randomized Experiment with a Long-Term Follow Up. Journal of Research in Crime and Delinquency, vol 42, no 3, pp 309-332.

Branson, C. E., Baetz, C. L., Horwitz, S. M. \& Hoagwood, K. E. (2017) Trauma-informed juvenile justice systems: A systematic review of definitions and core components. Psychological Trauma: Theory, Research, Practice, and Policy, vol 9, no 6, pp 635-646. 
Butts, J. \& Evans, D. N. 2011. Resolution, Reinvestment, and Realignment: Three Strategies for Changing Juvenile Justice. New York: John Jay College of Criminal Justice.

Castellani, P. (2005) From Snake Pits To Cash Cows: Politics and Public Institutions in New York, Albany: State University of New York Press.

Cate, S. (2016) Devolution, not decarceration: The limits of juvenile justice reform in Texas. Punishment \& Society, vol 18, no 5, pp 578-609.

Cheliotis, L. (2006) How iron is the iron cage of new penology? The role of human agency in the implementatino of criminal justice policy. Punishment and Society, vol 8, no 3, pp 313-40.

Cooperrider, D. L. \& Whitney, D. (2007). Appreciative Inquiry: A positive revolution in change, in Holman, P. \& Devane, T. (eds.) The Change Handbook. Berrett-Koehler Publishers.

Crawley, E. (2004) Doing Prison Work: The Public and Private Lives of Prison Officers, Devon: Willan Publishing.

DeMasi, M. \& Boyd, D. 2007. Behavior Support and Management: Coordinated Standards for Children's Systems of Care. Rensselaer, New York: Council on Children and Families.

Dowden, C. \& Tellier, C. (2004) Predicting work-related stress in correctional officers: A meta-analysis. Journal of Criminal Justice, vol 32, no 31-47.

Dunkel, F. (2015). Juvenile Justice and Crime Policy in Europe, in Zimring, F., Langer, M. \& Tanenhaus, D. (eds.) Juvenile Justice in a Global Perspective. New York: NYU Press.

Fader, J. (2008). Inside and Out: Community Reentry, Continuity and Change Among FormerlyIncarcerated Urban Youth. Ph.D., University of Pennsylvania.

Ference, S. (2008). OCFS wants to close underutilized youth facilities. News 10 Now.

Garland, D. (1985) The Criminal and his Science: A Critical Account of the Formation of Criminology at the End of the Nineteenth Century. The British Journal of Criminology, vol 25, no 2, pp 109-137.

Garland, D. (2013) Penality and the Penal State. Criminology, vol 51, no 3, pp 475-517.

Gatti, U., Tremblay, R. E. \& Vitaro, F. (2009) Iatrogenic effect of juvenile justice. The Journal of Child Psychology and Psychiatry, vol 50, no 8, pp 991-998.

Goodman, P., Page, J. \& Phelps, M. (2017) Breaking the Pendulum: The Long Struggle Over Criminal Justice, New York: Oxford University Press.

Gottschalk, M. (2010) Cell blocks \& red ink: mass incarceration, the great recession \& penal reform. Daedalus, vol, no Summer, pp 62-73.

Government Accountability Office 2009. Seclusions and Restraints: Selected Cases of Death and Abuse at Public and Private Schools and Treatment Centers. Washington DC: United States Government Accountability Office.

Grasso, A. (2017) Broken Beyond Repair: Rehabilitative Penology and American Political Development. Political Research Quarterly, vol 70, no 2, pp.

Gray, P. (2013) Assemblages of penal governance, social justice and youth partnerships. Theoretical Criminology, vol 17, no 4, pp 517-534.

Hannah-Moffat, K. (2006) Pandora's Box: Risk/Need and Gender-Responsive Corrections. Criminology \& Public Policy, vol 5, no 1, pp 183-192.

Harcourt, B. 2014. The Systems Fallacy: From Operations Research to Contemporary CostBenefit Analysis: The Perils of Systems Analysis, Past and Present. Harvard Law School Criminal Justice Roundtable. Cambridge, MA.

Hirschorn, L. (1988) The Workplace Within: Psychodynamics of Organizational Life, Cambridge, Massachusetts: The MIT Press. 
Horowitz, J. \& Carlock, A. 2017. Juvenile Commitment Rate Falls by Half Nationally in 10 Years. Pew Charitable Trusts.

Inderbitzen, M. (2006) Guardians of the State's Problem Children. The Prison Journal, vol 86, no 4, pp 431-451.

Kelly, L. \& Armitage, V. (2014) Diverse Diversions: Youth Justice Reform, Localized Practices, and a 'New Interventionist Diversion'? Youth Justice, vol, no.

King, D. (2010). 'Culture of Violence' Plagues New York's Juvenile Prisons. Gotham Gazette.

King, R. S., Mauer, M. \& Huling, T. 2003. Big Prisons, Small Towns: Prison Economics in Rural America. Washington, DC: The Sentencing Project.

Kruttschnitt, C. (2016) THE POLITICS, AND PLACE, OF GENDER IN RESEARCH ON CRIME*. Criminology, vol 54, no 1, pp 8-29.

Lacey, N. \& Soskice, D. (2015) Crime, punishment and segregation in the United States: The paradox of local democracy. Punishment \& Society, vol 17, no 4, pp 454-481.

Larson, K. \& Carvente, H. 2017. Juvenile Justice Systems Still Grappling with the Legacy of the "Superpredator" Myth. Think Justice Blog. New York, NY: Vera Institute of Justice.

Leidner, R. (2010). Work Cultures, in Hall, J., Grindstaff, L. \& Lo, M.-C. (eds.) Handbook of Cultural Sociology. New York: Routledge.

Liebling, A. \& Arnold, H. (2004) Prisons and Their Moral Performance: A Study of V alues, Quality, and Prison Life, Oxford: Oxford University Press.

Liebling, A. \& Price, D. (2001) The Prison Officer, Leyhill: Prison Service and Waterside Press.

Lipsky, M. (1980) Street-Level Bureaucracy: Dilemmas of the Individual in Public Services, New York: Sage.

McAvoy, K. (2008). Union blasts state over Tryon cuts. The Leader Herald.

McCarthy, P., Schiraldi, V. \& Shark, M. 2016. The Future of Youth Justice: A CommunityBased Alternative to the

Youth Prison Model Cambridge, MA: Executive Session on Community Corrections/Harvard Kennedy School.

McGarrell, E. F. (1988) Juvenile Correctional Reform: Two Decades of Policy and Procedural Change, Albany: State University of New York.

Mendel, R. 2010. The Missouri Model: Reinventing the Practice of Rehabilitating Youthful Offenders. Baltimore: Annie E. Case Foundation.

Moore, S. (2009). Missouri System Treats Juvenile Offenders With a Lighter Hand. The New York Times.

Morrill, C. \& Rudes, D. 2010. How Resistance Matters in Public Bureaucracies: Collective Moral Identities and the Micro-Politics of Legal and Policy Change among Parole Agents, Social Workers, and Teachers. Law and Society Association. Chicago.

Myers, R. (2013) The Biographical and Psychic Consequences of 'Welfare Inaction' for Young Women in Trouble with the Law. Youth Justice, vol 13, no 3, pp 218-233.

Nagin, D., Cullen, F. Jonson, C. (2009). Imprisonment and Reoffending, in Tonry, M. (ed.) Crime and Justice: An Annual Review of Research. Chicago: University of Chicago Press.

National Juvenile Justice Network \& Texas Public Policy Foundation 2013. The Comeback States: Reducing youth incarceration in the United States. Washington, DC: National Juvenile Justice Network,.

New York Times. (2010). Juvenile Injustice. The New York Times.

O'Malley, P. (2010) Crime and Risk, London: Sage. 
OCFS 2008. 2008 Annual Report: Youth Placed in Custody. Rensselaer, NY: Office of Children and Family Services, Division of Juvenile Justice and Opportunities for Youth.

Office of Children and Family Services 2016. 2016 Annual Report Youth in Care.

Rensselaer, NY: Office of Children and Family Service, Division of Juvenile Justice and Opportunities for Youth.

Page, J. (2011) The Toughest Beat: Politics, Punishment, and the Prison Officers Union in California, New York: Oxford University Press.

Pfaff, J. (2017) Locked In: The True Causes of Mass Incarceration and How to Achieve Real Reform New York: Basic Books.

Phelps, M. (2016) Possibilities and Contestation in Twenty-First-Century US Criminal Justice Downsizing. Annual Review of Law and Social Science, vol 12, no 153-170.

Phoenix, J. (2009). Beyond Risk Assessment: The Return of Repressive Welfarism?, in Mcneill, F. \& Barry, M. (eds.) Youth Offending and Youth Justice. London: Jessica Kingsley Publishers.

ReadMedia. (2012). CSEA Challenges Close to Home Initiative over Criminal Background of Youth. Post Star.

Rubin, A. \& Phelps, M. S. (2017) Fracturing the penal state: State actors and the role of conflict in penal change. Theoretical Criminology, vol 21, no 4, pp 422-440.

Rudes, D. S., Lerch, J. \& Taxman, F. S. (2011) Implementing a Reentry Framework at a Correctional Facility: Challenges to the Culture. Journal of Offender Rehabilitation, vol 50, no 8, pp 467-491.

Ryan, L. \& Schiraldi, V. 2018. Why do we still imprison youth? The Crime Report.

Sampson, R. J. \& Raudenbush, S. W. (2004) Seeing Disorder: Neighborhood Stigma and the Social Construction of "Broken Windows". Social Psychology Quarterly, vol 67, no 4, pp 319-342.

Schiraldi, V. (2018). Raising Age to 23: It Works for the Dutch. The Crime Report.

Sim, J. (2010) Thinking about state violence. Criminal Justice Matters, vol, no 82, pp.

Stuart, F. (2016) Down Out \& Under Arrest: Policing and Everyday Life in Skid Row, Chicago: University of Chicago Press.

Task Force on Transforming Juvenile Justice 2009. Charting a New Course: A Blueprint for Transforming Juvenile Justice in New York State. New York: Vera Institute of Justice.

Thompson, H. A. (2011) Rethinking Working-Class Struggle through the Lens of the Carceral State: Toward a Labor History of Inmates and Guards. Labor, vol 8, no 3, pp $15-45$.

Tracy, S. J. (2004) Dialectic, Contradiction, or Double Bind? Analyzing and Theorizing Employee Reactions to Organizational Tension. Journal of Applied Communication Research, vol 32, no 2, pp 119-146.

Ward, G. \& Kupchik, A. (2008) What Drives Juvenile Probation Officers?: Relating Organizational Contexts, Status Characteristics, and Personal Convictions to Treatment and Punishment Orientations. Crime \& Delinquency, vol 56, no 1, pp 35-69.

Watkins-Hayes, C. (2009a) The New Welfare Bureaucrats: Entanglements of Race, Class, and Policy Reform, Chicago: University of Chicago Press.

Watkins-Hayes, C. (2009b) Race-ing the Bootstrap Climb: Black and Latino Bureaucrats in Post-Reform Welfare Offices. Social Problems, vol 56, no 2, pp 285-310.

Werth, R. (2017) Individualizing Risk: Moral Judgement, Professional Knowledge and Affect in Parole Evaluations. The British Journal of Criminology, vol 57, no 4, pp 808-827. 
Western, B. (2007). Introduction to the Princeton Classic Edition, in Sykes, G. M. (ed.) The Society of Captives. Princeton, N.J.: Princeton University Press.

Wilson, J. Q. \& Kelling, G. L. 1982. Broken Windows. Atlantic Monthly.

Wurtmann, B. 2012. Taxpayers footing higher OT bill at OCFS. WNYT.

Wynne, J. M. (1978) Prison Employee Unionism: The Impact on Correctional Administration and Programs, Washington, DC: Naitonal Institute of Law Enforcement and Criminal Justice, Law Enforcement Assistance Administration.

ii Two of the facilities were not in existence in October of 2009 so comparative data could not be obtained for them. 